\title{
Sistem Absensi Menggunakan Teknologi Qr Code Dan Face Recognition
}

\author{
Andi Asvin Mahersatillah Suradi ${ }^{1}$, Andi Syarwani ${ }^{2}$ \\ ${ }^{1,2}$ Program Studi Teknik Elektro \\ Universitas Hasanuddin \\ e-mail: *1 andiaspin3@gmail.com, ${ }^{2}$ syarwaniandi@gmail.com
}

\begin{abstract}
Abstrak
Buku atau catatan daftar hadir merupakan salah satu bukti bahwa mahasiswa tersebut telah hadir dalam suatu perkuliahan. Dengan menandai catatan daftar hadir tersebut mahasiswa dinilai telah hadir dan melakukan perkuliahan. Akan tetapi sistem absensi perkuliahan yang bersifat konvensional dapat menimbulkan beberapa kecurangan dikalangan mahasiswa serta rawan kesalahan data. Untuk itu diperlukan suatu sistem absensi yang realtime dari segi pencatatan dan dapat menghindari kecurangan. QR Code dan Face recognition merupakan salah satu metode yang mampu untuk menggantikan sistem absensi konvensional. QR Code menggunakan library Zxing dan Face Recognition menggunakan library EmguCV sehingga aplikasi ini berhasil digunakan. Dengan integrase MySQL untuk penyimpanan data mahasiswa, dosen, maupun perkuliahan, di database ini menjadi catatan absensi yang dapat langsung digunakan untuk pelaporan absensi mahasiswa. Hasil dari penelitian ini menunjukkan bahwa sistem dapat mencatat kehadiran mahasiswa melalui pemindaian QR Code dan Face Recognition.
\end{abstract}

Kata kunci : QR Code, Zxing, Face Recognition, EmguCV

\begin{abstract}
The attendance list book or note is one proof that the student has attended a lecture. By marking the note on the attendance list, students are assessed as having attended and conducting lectures. However, the conventional lecture attendance sistem can cause some fraud among students and is prone to data errors. For that, we need a realtime attendance sistem in terms of recording and can avoid fraud. QR Code and Face recognition are methods that can replace conventional attendance sistems. QR Code uses the Zxing library and Face Recognition uses the EmguCV library so that this application is successfully used. With the MySQL integration for storing student, lecturer, and lecture data, this database becomes an attendance record that can be directly used for student attendance reporting. The results of this study indicate that the sistem can record student attendance through scanning $Q R$ Code and Face Recognition.
\end{abstract}

Keywords : QR Code, Zxing, Face Recognition, EmguCV

\section{PENDAHULUAN}

Sistem perkuliahan sangat penting bagi mahasiswa. Dengan mengikuti perkuliahan, mahasiswa bisa mendapatkan beberapa ilmu tentang bidang studi yang diminatinya sehingga dirinya mendapatkan nilai tambah dari bidang studi tersebut. Buku atau catatan daftar hadir merupakan salah satu bukti bahwa mahasiswa tersebut telah hadir dalam suatu perkuliahan. Dengan menandai catatan daftar hadir tersebut mahasiswa dinilai telah hadir dan melakukan perkuliahan. Akan tetapi sistem absensi perkuliahan yang bersifat konvensional dapat menimbulkan beberapa kecurangan di kalangan mahasiswa. Seringkali mahasiswa memanfaatkan celah dan bekerjasama untuk melakukan kecurangan, misalnya menitipkan absen 
pada teman padahal dirinya tidak mengikuti perkuliahan tersebut. Tentunya itu sangat merugikan pihak orang tua dari mahasiwa yang telah membayar perkuliahan.

Disamping itu dengan sistem absensi perkuliahan yang bersifat konvensional diperlukan tambahan pegawai untuk menyalin ulang semua data mahasiswa yang mengikuti perkuliahan setiap harinya. Hal tersebut membutuhkan waktu serta tenaga yang cukup lama mengingat pekerjaan dilakukan akan terus berulang setiap jam kerja hingga selesai jam kerja. Ketidaksesuaian data absensi dapat merugikan mahasiswa. Seringkali terdapat perbedaan antara absensi yang tertera pada buku/ catatan daftar hadir dengan absensi yang terdapat pada laporan. Sering terjadinya kesalahan dalam penyalinan tersebut merupakan salah satu faktor yang membuat data asli dan data masukan berbeda. Data yang terlalu banyak memungkinkan terjadinya human error.

\section{TINJAUAN PUSTAKA}

\subsection{QR Code}

QR Code adalah barcode dua dimensi yang dapat dibaca oleh smartphone. Ini memungkinkan untuk menyandikan lebih dari 4.000 karakter dalam barcode dua dimensi. Kode QR dapat digunakan untuk menampilkan teks kepada pengguna, untuk membuka URL, menyimpan kontak ke buku alamat atau untuk menulis pesan teks. Sistem memerlukan proses login sederhana oleh instruktur kelas melalui Modul Server untuk menghasilkan kode QR dengan informasi spesifik [1].

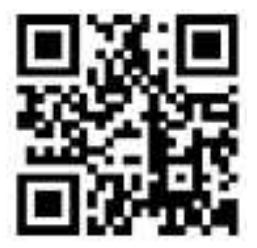

Gambar 1. Contoh QR Code

Desainer QR Code menambahkan empat kotak besar sebagai standar yang dipakai oleh semua QR Code. Tiga kotak dengan ukuran besar membantu kamera menentukan posisi dari QR Code. Sedangkan kotak keempat berukuran kecil digunakan untuk menormalkan ukuran gambar, sudut pandang dan orientasi gambar.

\subsection{ZXing}

Zxing adalah perpustakaan open-source berbasis Java yang populer untuk decoding QR /barcode, yang juga merupakan sebuah library image processing dalam bahasa pemrograman Java untuk barcode multi-format 1D/2D yang open-source. Fokus Zxing, adalah menggunakan built-in kamera pada ponsel untuk barcode foto dan membaca sandi pada perangkat tanpa berkomunikasi dengan server. Decoder Library ZXing support untuk jenis-jenis barcode sebagai berikut: UPC-A, UPC-E, EAN-8, EAN-13, Code 39, Kode 93, Code 128, ITF, Codabar, MSI, RSS-14 (semua varian), QR Code, Data Matrix, Aztec dan PDF417 [2].

Encoder Library ZXing support untuk jenis-jenis Barcode sebagai berikut: UPC-A, EAN-8, EAN-13, Code 39, Code 128, ITF, Codabar, Plessey, MSI, QR Code, PDF-417, Aztec, data matrix. Library zxing dibangun atas beberapa bagian komponen yaitu:

- Javase : khusus kode klien J2SE.

- Android : klien dari Android, yang disebut Barcode Scanner.

- Androidtest : aplikasi uji Android.

- Android-integration : mendukung integrasi dengan aplikasi barcode Scanner melalui internet. 
- Zxingorg : nama lain dari sumber zxing.org/w.

- Zxing.appspot.com : nama lain sumber barcode generator berbasis web.

\subsection{Face Recognition}

Pengenalan wajah merupakan salah satu pendekatan pengenalan pola untuk keperluan identifikasi wajah seseorang dengan pendekatan biometrik. Suatu biometrik bersifat unik sehingga dapat digunakan untuk mengenali identitas seseorang. Biometrik fisik berasal dari pengukuran dan data yang ada langsung dari bagian manusia misalnya pengenalan sidik jari, pengenalan wajah, iris, retina, dan tangan. Salah satu cara yang digunakan dalam pengenalan wajah yaitu dengan membandingkan wajah dari gambar yang dipilih atau video dengan basis data wajah [3].

\subsection{EmguCV}

EmguCV adalah suatu library open source lintas platform. EmguCV dapat memanggil fungsi-fungsi di openCV library pada image processing. EmguCV bisa digunakan dengan banyak bahasa pemrograman seperti $\mathrm{C}++, \mathrm{C \#}, \mathrm{VB}$, IronPhyton dan lain-lain. Namun ada dua konsep penting yang perlu diketahui terlebih dahulu sebelum menggunakan EmguCV.

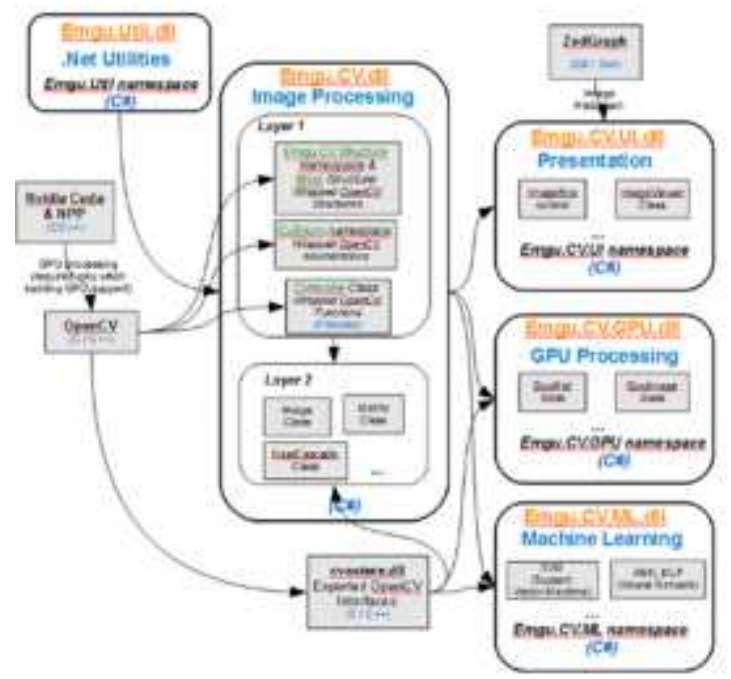

Gambar 2. Arsitektur EmguCV

Yang pertama mengenai layer pada EmguCV, Emgu CV terdri dari 2 layer yaitu basic layer dan second layer. Basic Layer mengandung fungsi, struktur dan enumerasi yang secara langsung merefleksikan apa yang ada di OpenCV. Dengan adanya layer inilah kita bisa memanggil fungsi-fungsi pada OpenCV dengan bahasa pemrograman C\#. Sedangkan second layer mengandung kelas-kelas yang memanfaatkan keunggulan teknologi .NET. Konsep kedua yang perlu dipahami yaitu mengenai code mapping, yaitu bagaimana kode-kode dalam OpenCV dipetakan kedalam EmguCV [4].

\subsection{Penelitian Terkait}

Sistem absensi menggunakan QR Code dan juga Face Recognition telah banyak diimplementasikan baik untuk akademik seperti absen siswa, maupun di dunia industri untuk pengenalan pegawai. Beberapa diantaranya penelitian tersebut. 
- Taqwa, dkk, mengaplikasikan penggunaan QR Code untuk absensi dosen. Pengelolaan data menggunakan pemrograman PHP dan MySQL. Sedangkan akses sistem yang ditampilkan di website dibaca menggunakan aplikasi android. Hasilnya sistem yang dapat digunakan untuk absensi dosen [5].

- Yusuf, dkk, membangun aplikasi absensi menggunakan pengenalan wajah. Metode eigenface ditawarkan dan hasil absen ditampilkan dalam bentuk format excel [6].

- Aryani, dkk, membuat prototype sistem absensi berbasis face recognition menggunakan lirary eigenface dengan memanfaatkan mikrokontroler aduino uno sebagai tempat pemrosesan data dari inputan perangat webcam [7].

\section{METODE PENELITIAN}

\subsection{Tahapan Penelitian}

- Studi literatur mengenai penelitian yang memiliki relevansi dengan penelitian ini serta metode yang akan digunakan.

- Melakukan survei lokasi penelitian yang bertempat di Departemen Teknik Elektro, Universitas Hasanuddin, Kab. Gowa untuk pengambilan data dan kegiatan observasi awal hingga akhir penelitian.

- Setelah melakukan survei, selanjutnya proses pengambilan data baik dari hasil survei maupun sumber-sumber dari internet.

- Perancangan sistem dimulai pada saat data sudah didapatkan sampai pada tahap akhir seiring dengan pencarian literatur-literatur menggunakan algoritma atau metode yang sudah ditentukan.

- Melakukan pengujian dan analisa sistem yang telah dibuat berdasarkan metode yang digunakan dan mengevaluasi hasil yang didapatkan.

\subsection{Jenis Penelitian}

Terdapat dua jenis penelitian yang digunakan dalam rangka penyelesaian masalah yang dihadapi, yaitu:

- Penelitian pustaka yaitu penelitian yang dilakukan dengan mengambil beberapa definisi dan konsep yang diperlukan dan mendukung kegiatan/penulisan penelitian ini.

- Penelitian lapangan yaitu penelitian yang dilakukan dengan mengunjungi langsung lokasi tempat penelitian. Di tempat penelitian tersebut, penulis melakukan pengamatan terkait proses absensi.

\subsection{Desain Sistem}

Desain sistem yang digunakan adalah model SDLC yang merupakan singkatan dari Systems Development Life Cycle. Salah satu metode yang popular yang digunakan dalam model ini yaitu waterfall yang terdiri dari 5 tahapan seperti pada gambar 3.

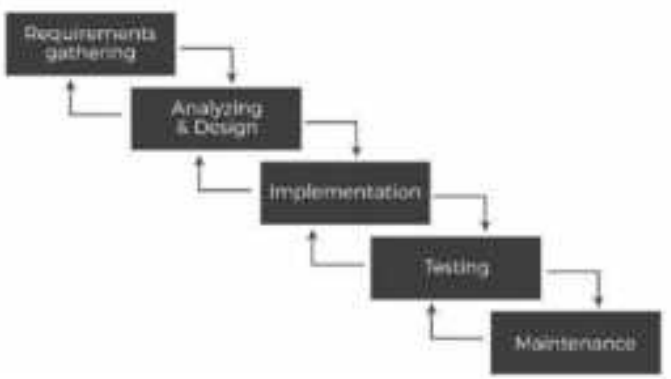

Gambar 3. Arsitektur Waterfall 
- Requirements Gathering, pada tahap ini peneliti mengumpulkan data primer atau sekunder untuk mengetahui kebutuhan pengguna yang berkaitan dengan penelitian.

- Analyzing and Design, tahap ini peneliti melakukan analisis untuk menentukan kebutuhan sistem serta merancang bagaimana cara kerja sistem, rancangan antarmuka, dan perancangan database.

- Implementation, tahap ini melakukan implementasi pada sistem yang telah dibuat.

- Testing, merupakan proses pengujian sistem untuk melihat respon dari semua masukan yang diberikan.

- Maintenance, tahapan ini berkaitan dengan pemeliharaan sistem serta memeriksa bug [8].

\subsection{Instrumen Penelitian}

A. Perangkat Keras :

1. Laptop MSI Core i7

2. Samsung J7 digunakan untuk menjalankan aplikasi berbasis android secara real device.

B. Perangkat Lunak:

1. Android Studio versi 4.0 include Emulator untuk menjalankan aplikasi berbasis android dengan sistem operasi yang berbeda agar peneliti bisa melihat perbandingannya.

2. Visual Studio Code untuk mengetikkan kode program yang berjalan berbasis web.

3. Appserv (Database MySQL)

4. Java Standar Development Kit (SDK).

5. Adobe Photoshop CC 2015 untuk membuat diagram-diagram dalam UML.

C. Bahasa Pemrograman:

1. Java untuk aplikasi berbasis android di Android Studio.

2. PHP untuk aplikasi berbasis web.

3. VB.Net untuk aplikasi pengenalan wajah.

D. Framework:

1. Untuk aplikasi android tidak menggunakan framework (native app)

2. Untuk aplikasi berbasis web menggunakan framework Bootstrap untuk penataan layput (HTML dan CSS).

\section{PERANCANGAN SISTEM}

Aplikasi yang dibuat dalam tugas ini merupakan aplikasi absensi perkuliahan mahasiswa dengan QR Code dan pengenalan wajah. Aplikasi perkuliahan mahasiswa ini merupakan aplikasi berbasis mobile untuk QR Code sedangkan untuk pengenalan wajah berbasis desktop. Aplikasi ini berupa prototipe misalnya akses login dan penanda pertemuan yang dilakukan oleh dosen.

\subsection{Identifikasi Pengguna}

Identifikasi pengguna mendifinisikan entitas-entitas yang terlibat dan berinteraksi langsung dengan sistem. Berdasarkan deskripsi umum sistem yang telah dijelaskan pada bagian sebelumnya, maka pengguna yang akan menggunakan aplikasi ini ada empat, yaitu:

- Administrator, merupakan pengguna yang bertanggungjawab terkait dengan data tata usaha, dosen, mahasiswa, mata kuliah, kelas, dan jadwal perkuliahan. 
- Tata usaha, merupakan pengguna yang bertanggungjawab dalam terkait dengan data dosen, mahasiswa, mata kuliah, kelas, dan jadwal perkuliahan

- Dosen, pengguna yang mengatur fitur pada saat perkuliahan, seperti mengaktifkan fitur absensi agar dapat digunakan oleh mahasiswa, dan pengisian kali pertemuan.

- Mahasiswa merupakan pengguna yang hanya memiliki akses untuk melakukan dan melihat absensi.

\subsection{Perancangan Arsitekstur}

Arsitektur aplikasi dapat dilihat pada Gambar 4. Berikut penjelasan arsitektur sistem yang terdapat pada Gambar 4:

- Administrator atau tata usaha mengelola data-data yang dibutuhkan sistem. Seperti data perkuliahan, nama-nama mahasiswa per mata kuliah, nim, nama dan konsentrasi jurusan mahasiswa, serta nama dosen per mata kuliah.

- Administrator atau tata usaha mendapatkan data rekapitulasi kehadiran, file ekstraksi data kehadiran, dan data yang dikelola.

- Dosen mengaktifkan absensi dan menentukan kali pertemuan.

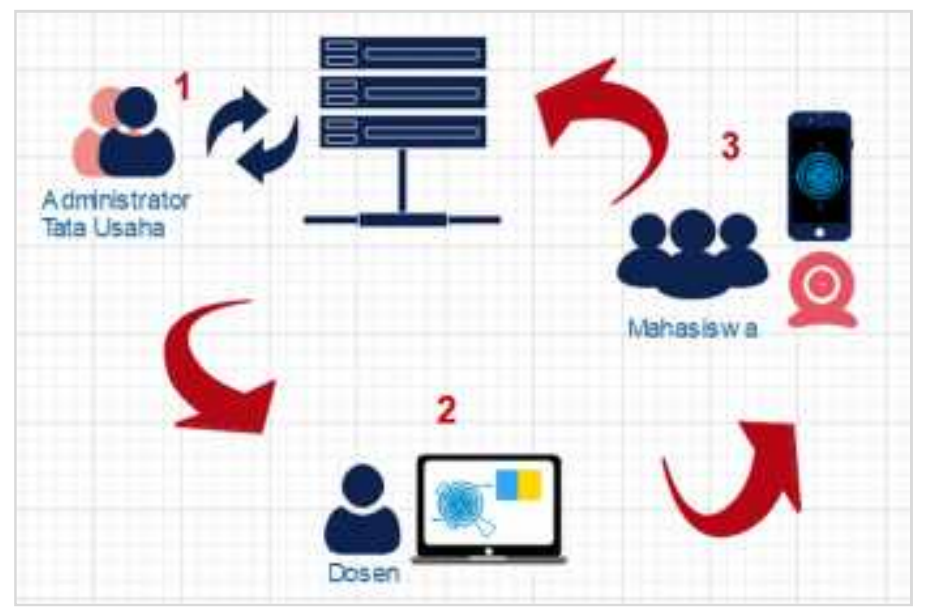

Gambar 4. Arsitektur Perancangan Sistem

- Setelah dosen mengaktifkan pengisian absen, mahasiswa memulai absensi. Hal ini dapat dilakukan dengan dua cara; cara pertama mahasiswa melakukan scanning QR Code melalui aplikasi yang terdapat di smartphone mahasiwa, ketika scanning berhasil maka akan muncul pesan success pada absensi. Yang kedua yaitu menggunakan face recognition, dengan menghadapkan wajah ke depan computer. Dengan menekan tombol start, webcam akan diaktifkan dan menangkap wajah mahasiswa. Ketika aplikasi mengenali wajah mahasiswa maka aplikasi akan menutup dan data mahasiswa sudah terupdate berstatus hadir di data base absen.

\subsection{Proses Pemasukan Data}

Proses masukan data wajah pada sistem dapat dilihat pada Gambar 5. Pada proses ini, pengguna mengambil foto wajahnya secara langsung melalui webcam. Sistem akan mendeteksi wajah dengan metode Haarcascade dari library EmguCV. Wajah yang dideteksi adalah wajah yang menghadap ke depan, pada pencahayaan yang baik, dan wajah yang tidak terhalangi oleh kacamata, masker, ataupun objek lainnya. Kemudian pengguna meng-capture wajah yang dideteksi dan sistem akan menampilkan wajah hasil capture. Setelah itu, data wajah akan disimpan pada basis data. 
Adapun untuk sistem QR Code, mahasiswa tidak perlu melalukan pemasukan data untuk absensi. Karena sistem yang akan berjalan pada absen menggunakan QRCode hanya mencocokkan nim yang dimasukkan pada saat melakukan scanning QR Code.

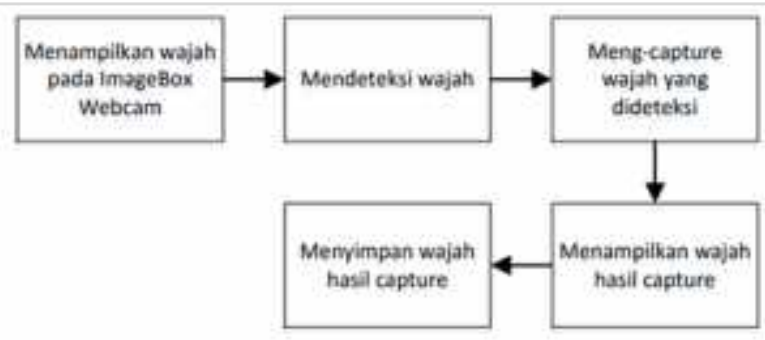

Gambar 5. Alur Proses registrasi wajah mahasiswa

\subsection{Perancangan Basis Data}

Basis data yang dibangun pada aplikasi ini menggunakan sistem manajemen basis data relasional MySQL. Data-data yang disimpan dalam MySQL diantaranya data absensi mahasiswa, data mata kuliah, data jadwal perkuliahan, data mahasiswa, data foto mahasiswa, data mahasiswa per kelas, data dosen, serta data login yang digunakan untuk administrator dan tata usaha. Perancangan basis data dimodelkan dalam diagram model konsep basis data atau Conceptual Data Model (CDM).

\subsection{Bagan Sistem}

Bagan ini serta use case adalah sebagai gambaran bagi pembaca untuk memahami langkah-langkah serta cara kerjs dari sistem yang dibuat.

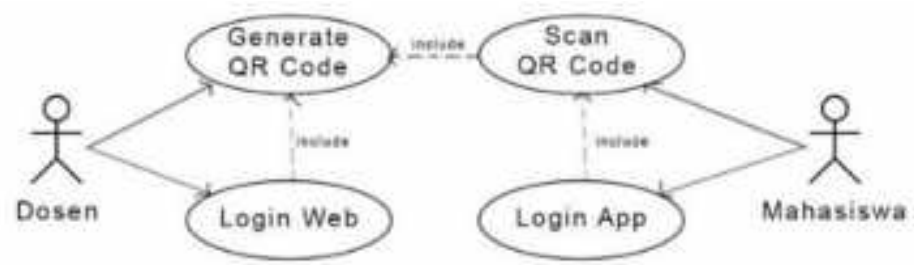

Gambar 6. Use Case Dosen dan Mahasiswa 


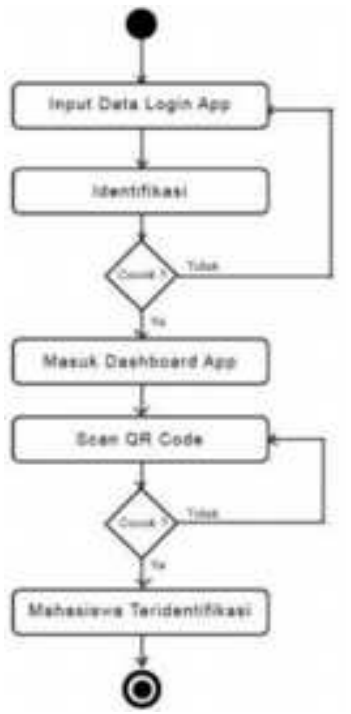

Gambar 7. Activity Diagram Login

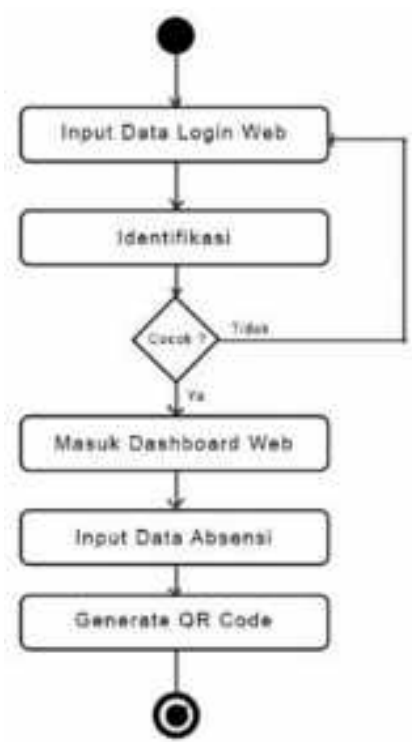

Gambar 8. Activity Diagram Generate QR Code Dosen

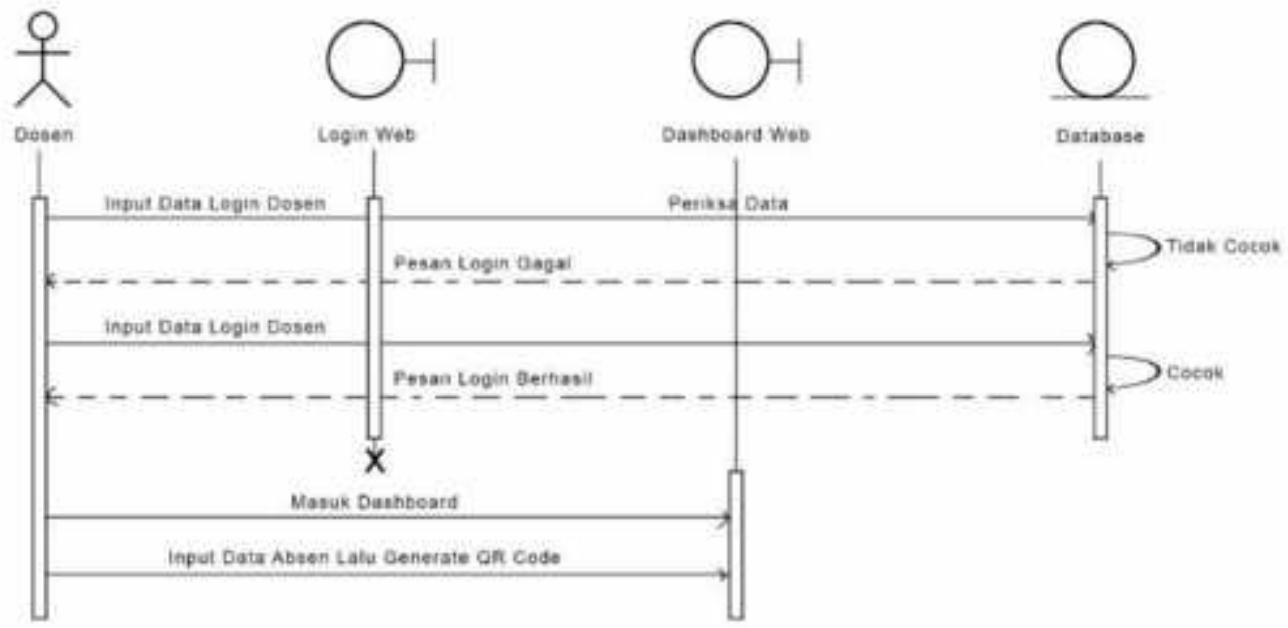


Gambar 9. Sequence Diagram Dosen

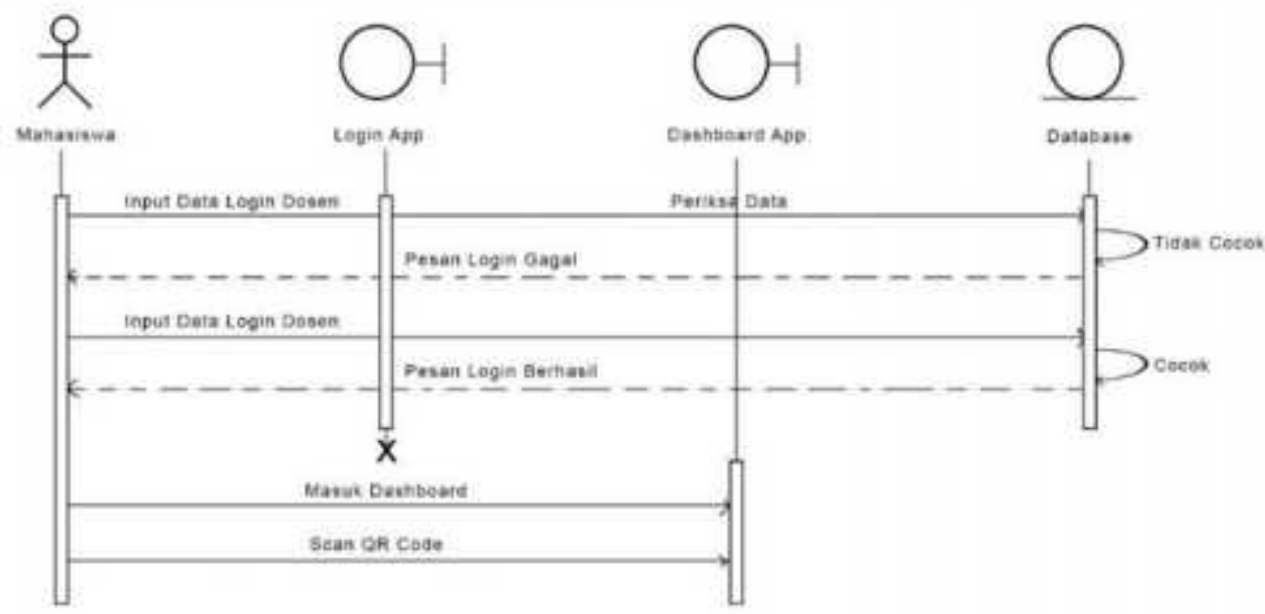

Gambar 10. Sequence Diagram Mahasiswa

\section{HASIL DAN PEMBAHASAN}

Halaman login dan pengaktifan absen di buat berbasis web. Data yang dimasukkan sebelumnya telah dimasukkan dalam database, seperti nama mata kuliah, dosen pengampuh, dan pass.

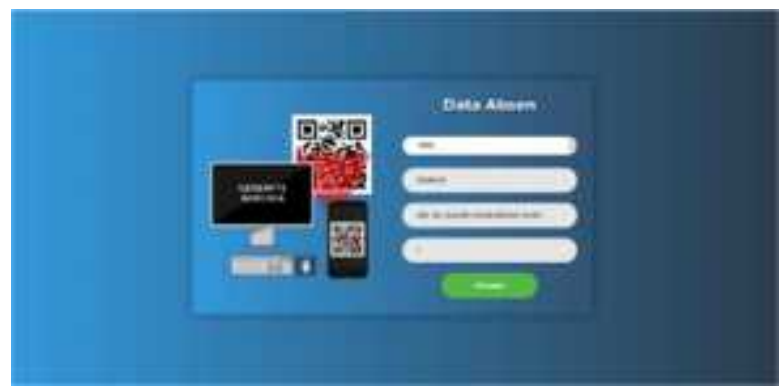

Gambar 11. Layout Input Dosen

Pada gambar 11 merupakan gambar dengan pola QR Code yang nantinya akan dilakukan proses pemindaian (scanning) oleh mahasiswa yang hadir. Dalam gambar tersebut juga akan menampilkan nama mata kuliah.

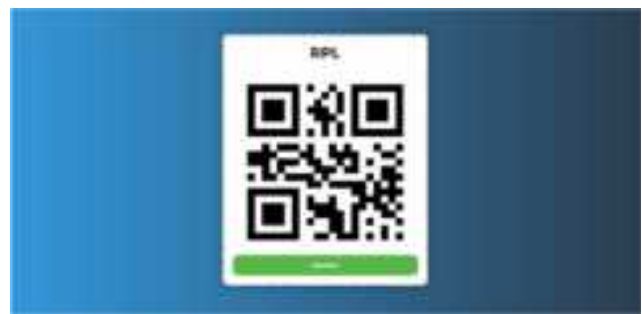

Gambar 12. Layout QR Code

Pengujian pada QR Code dengan mengaktifkan aplikasi yang ada pada smartphone. Mahasiswa diminta untuk memasukkan nim dan password dan menekan tombol login untuk proses identifikasi. Pada saat proses login selesai maka mahasiswa akan masuk ke halaman dashboard, dan disitu akan ada tombol scan untuk mengaktifkan kamera dan mulai melakukan 
proses pemindaian (scanning) pada QR Code yang diberikan oleh dosen. Pada gambar 15 merupakan hasil dari proses pemindaian (scanning) terhadap QR Code yang sesuai yang disertai dengan tanggal dan waktu. Dan proses ini menandai bahwa mahasiwa berhasil melakukan absen.

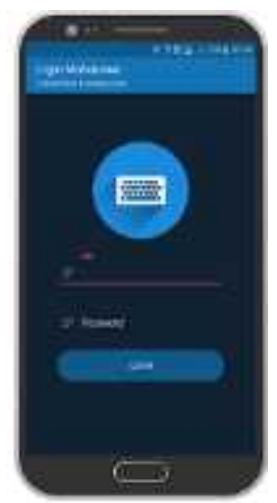

Gambar 13. Login Mahasiswa

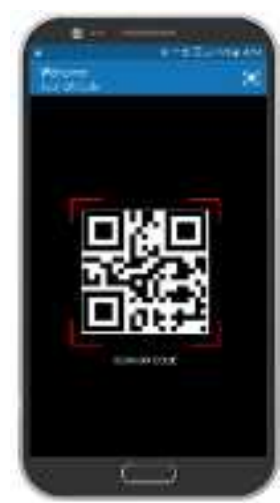

Gambar 14. Scanning QR Code

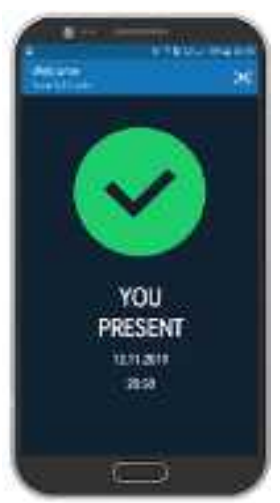

Gambar 15. Absensi berhasil

Untuk sistem face recognition, ada dua tahap, yakni proses training dan pengujian. Ketika aplikasi di buka, ada tiga tombol utama, yakni stop, simpan, training wajah. Tombol stop dan simpan mewakili proses pengujian. Sedangkan tombol training wajah mewakli proses training.

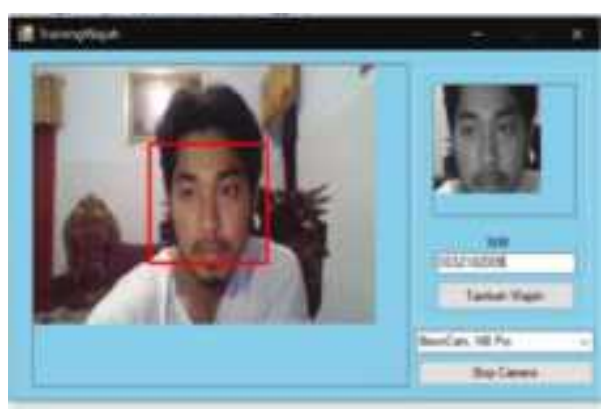

Gambar 16. Proses Training Wajah

Proses training bekerja dengan cara sebagai berikut. Saat baru akan melakukan registrasi wajah, maka tombol training wajah ditekan. Akan muncul jendela baru yang akan meminta nim untuk dicocokkan dengan data base dan sebagai penanda pemilik wajah. Setelah nim diisi, tekan tombol tambah wajah, dan setelah beberapa detik tekan tombol stop camera. Proses training ini berakhir dengan berhasil memasukkan dan menandai wajah tersebut sesuai dengan nim yang dimasukkan. 


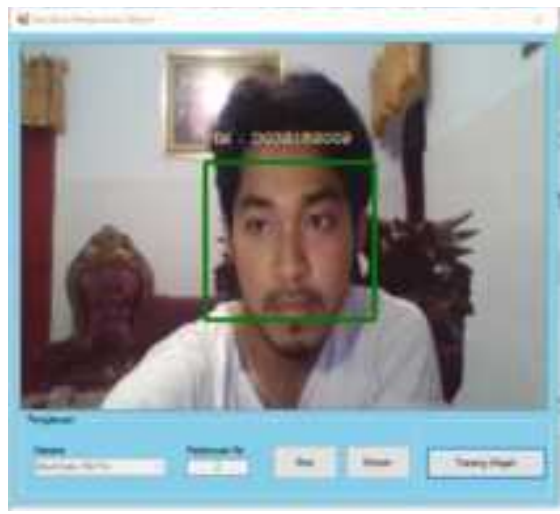

Gambar 17. Pengenalan wajah

Proses pengujian dengan aplikasi secara otomatis mendeteksi dan memperlihatkan nim pada layer saat webcam membaca wajah yang tertangkap kamera. Ketika sistem berhasil mengenali wajah yang tertangkap oleh webcam, maka tekan tombol stop untuk mengakhiri proses pembacaan. Dan untuk menandai absen kehadiran, tekan tombol simpan. Untuk sistem ini, pertemuan yang aktif akan otomatis muncul sesuai dengan kali pertemuan yang telah diset oleh Dosen saat mengaktifkan sistem.

\section{PENGUJIAN SISTEM}

Pengujian sistem yang dilakukan adalah pengujian black box. Pengujian black box memainkan peran penting dalam pengujian perangkat lunak, ini membantu validasi fungsionalitas keseluruhan sistem. Pengujian kotak hitam dilakukan berdasarkan persyaratan pelanggan - sehingga persyaratan yang tidak lengkap atau tidak dapat diprediksi dapat dengan mudah diidentifikasi dan dapat diatasi nanti. Pengujian black box dilakukan berdasarkan perspektif pengguna akhir. Pentingnya pengujian kotak hitam ini menangani input yang valid dan tidak valid dari perspektif pelanggan [9].

Tabel 1. Pengujian Sistem Menggunakan Black Box

\begin{tabular}{|c|l|l|c|}
\hline No & \multicolumn{1}{|c|}{ Jenis Pengujian } & \multicolumn{1}{|c|}{ Respon Sistem } & Status \\
\hline 1 & $\begin{array}{l}\text { Login pengguna (Dosen dan } \\
\text { Mahasiswa) }\end{array}$ & $\begin{array}{l}\text { Berhasil masuk ke dalam dashboard } \\
\text { pengguna. }\end{array}$ & Berhasil \\
\hline 2 & $\begin{array}{l}\text { Menyiapkan absensi harian } \\
\text { oleh dosen }\end{array}$ & $\begin{array}{l}\text { Data absensi tersimpan dan generate } \\
\text { QR Code }\end{array}$ & Berhasil \\
\hline 3 & $\begin{array}{l}\text { Pemindaian QR Code absensi } \\
\text { harian oleh mahasiswa }\end{array}$ & $\begin{array}{l}\text { QR Code terdeteksi dan mahasiswa } \\
\text { tercatat hadir berdasarkan NIM }\end{array}$ & Berhasil \\
\hline 4 & $\begin{array}{l}\text { Penambahan data wajah } \\
\text { mahasiswa pada sistem face } \\
\text { recognition }\end{array}$ & $\begin{array}{l}\text { Wajah berhasil dikenali berdasarkan } \\
\text { NIM }\end{array}$ & Berhasil \\
\hline 5 & $\begin{array}{l}\text { Training data wajah } \\
\text { mahasiswa yang tersimpan }\end{array}$ & $\begin{array}{l}\text { Wajah masing-masing mahasiswa } \\
\text { dapat dikenali dan menampilkan } \\
\text { label NIM }\end{array}$ & Berhasil \\
\hline 6 & $\begin{array}{l}\text { Pengenalan wajah mahasiswa } \\
\text { dan mencatat kehadiran }\end{array}$ & $\begin{array}{l}\text { Data absensi tersimpan berdasarkan } \\
\text { NIM mahasiswa dari proses } \\
\text { pengenalan wajah }\end{array}$ & Berhasil \\
\hline
\end{tabular}




\section{KESIMPULAN DAN SARAN}

\subsection{Kesimpulan}

Dari hasil selama proses perancangan, implementasi, serta pengujian aplikasi absensi perkuliahan mahasiswa dengan QR code dan pengenalan wajah, dapat diambil kesimpulan sebagai berikut:

a. Aplikasi berhasil dibangun dan terhubung dengan MySQL sebagai tujuan dari pembuatan aplikasi ini.

b. Aplikasi mampu mengenali wajah dan QR code yang diberikan untuk proses absensi.

c. Aplikasi mampu merekap data kehadiran mahasiwa secara transparan dan realtime sehingga dapat menjawab permasalahan terkait kesalahan penginputan data maupun kecurangan absen mahasiswa.

\subsection{Saran}

Aplikasi ini masih butuh pengembangan dan pengujian lebih lanjut untuk menguji dari segi keamanan dan kehandalan, karena bagaimana pun nantinya sistem ini akan diakses oleh banyak pengguna di waktu yang bersamaan, serta perlu ditingkatkan lagi akurasi dalam mengenali wajah mahasiswa.

\section{DAFTAR PUSTAKA}

[1] A. Patel, A. Joseph, S. Survase, and R. Nair, "Smart Student Attendance System Using QR Code," SSRN Electron. J., 2019, doi: 10.2139/ssrn.3370769.

[2] N. Bhardwaj, R. Kumar, R. Verma, A. Jindal, and A. P. Bhondekar, "Decoding algorithm for color QR code: A mobile scanner application," in 2016 International Conference on Recent Trends in Information Technology, ICRTIT 2016, 2016, doi: 10.1109/ICRTIT.2016.7569561.

[3] G. M. Zafaruddin and H. S. Fadewar, "Face recognition using eigenfaces," in Advances in Intelligent Systems and Computing, 2018.

[4] J. Ilmiah, I. Komputa, and E. Volume, "DENGAN IMPLEMENTASI METODE HISTOGRAM OF ORIENTED GRADIENTS DI LINGKUNGAN KANTOR WILAYAH KEMENTRIAN HUKUM DAN HAM Jurnal Ilmiah Komputer dan Informatika ( KOMPUTA )."

[5] E. Herlina and T. Hidayatulloh, "Penerapan QR Code Untuk Sistem Absensi Siswa SMP Berbasis Web," J. Teknol. dan Inf., vol. 7, no. 2, pp. 102-112, 1970, doi: 10.34010/jati.v7i2.865.

[6] M. Yusuf, R. V. H. Ginardi, and A. S. Ahmadiyah, "Rancang Bangun Aplikasi Absensi Perkuliahan Mahasiswa dengan Pengenalan Wajah," J. Tek. ITS, 2016, doi: 10.12962/j23373539.v5i2.17518.

[7] D. Aryani, M. N. Ihsan, and P. Septiyani, "Prototype Sistem Absensi Dengan Metode Face Recognition Berbasis Arduino Pada Smk Negeri 5 Kabupaten Tangerang," Semnasteknomedia Online, 2017.

[8] O. H. Lengkong et al., "Perancangan Online Examination System di Universitas Klabat Berbasis Web," e-Jurnal JUSITI (Jurnal Sist. Inf. dan Teknol. Informasi), vol. 9, no. 1, pp. 30-40, 2020, doi: 10.36774/jusiti.v9i1.641.

[9] S. Nidhra, "Black Box and White Box Testing Techniques - A Literature Review," Int. J. Embed. Syst. Appl., 2012, doi: 10.5121/ijesa.2012.2204. 